\title{
SEASONALITY AND THE FLIGHT OF PAUSSIDS \\ (COLEOPTERA) IN WEST AFRICA
}

\author{
BY DENNIS LESTON* \\ Biological Sciences Group \\ University of Connecticut \\ Storrs, CT 06268
}

\section{INTRODUCTION}

The paussids of this paper are the brown to black beetles, less than $8 \mathrm{~mm}$ in length, with aberrant antennae, variously regarded as a superfamily, family or subfamily within Carabidae, or of even lower taxonomic rank (Darlington, 1950): all are myrmecophiles. That these insects come to light is well known; that the emission of adults is seasonal rests, as far as I am aware, unreported.

In West Africa almost all insects are markedly seasonal in breeding, dispersal, population growth or other life history phenomena. The insect periodicities can be tied to underlying events at the primary producer and/or decomposer levels and it has been demonstrated that these are associated with periodicities delimited by a combination of rainfall and sunshine (not daylength) factors (Gibbs \& Leston, 1970; Leston, 1972, 1978; Leston \& Gibbs, 1971).

This paper presents the evidence for seasonality in Ghana, attempting to place the ultimate factors within the framework of West African phenology.

\section{MATERIAL AND METHOD}

The material was named using the collection of the British $\mathrm{Mu}$ seum (Nat. Hist.), London, where voucher specimens have been deposited. Taxonomists have clearly oversplit and the polytypic concept is not used by them.

Paussus cilipes Westwood - represented in West Africa by a subspecies other than the nominate.

\footnotetext{
*Present address: Department of Biology, University of Miami, Coral Gables, Florida 33124.

Manuscript received by the editor February 28, 1978.
} 
Paussus klugi Westwood - I suspect this and P. latreillei Westwood are conspecific, with the West African subspecies distinct from the nominate.

Paussus setosus Westwood.

Paussus sphaerocerus Afzel - outside of the sampling area this is abundant in the forest zone of Ghana.

Paussus spinicoxis Westwood - again, the West African form differs at the subspecies level from the nominate one.

Paussus sp 4 - this is not in the British Museum collection.

Platyrhopalopsis laevifrons (Westwood) - not found in my samples and known to me only from a specimen from Tumu, Upper Region (P. M. Room).

The seven listed comprise all the Paussina (Darlington's subtribe) found in Ghana.

A 125 watt Robinson ultraviolet light-trap was run for 400 days on the campus of the University of Ghana, Legon, Accra District, Ghana. The catches were grouped into 20-day classes, a method found of value in previous investigations (Gibbs \& Leston, 1970; Leston, 1973a). Sudden rain caused breakdowns on 14 nights: the figures were corrected by dividing the total for each species, for the relevant 20-day period, by the number of days actually sampled and adding this result for each missing sample - however, the overall results would have been the same even uncorrected. The original data sheets are deposited in the library of the Royal Entomological Society of London.

Legon, $5^{\circ} 40^{\prime} \mathrm{N}$, was once forested but is now an area of derived savanna at the edge of the dry Dahomey Gap. Food-farms, gardens and buildings cover the region but once shade has been artificially reestablished forest zone crops such as cocoa and robusta coffee can be grown successfully.

\section{RESULTS}

Numbers caught were

1. Paussus spinicoxis 758

2. P. sphaerocerus 165

3. P. cilipes 67

4. P. setosus 54

5. P. klugi 13

6. $P . \operatorname{sp~} 4 \quad 6$

Total 1063 


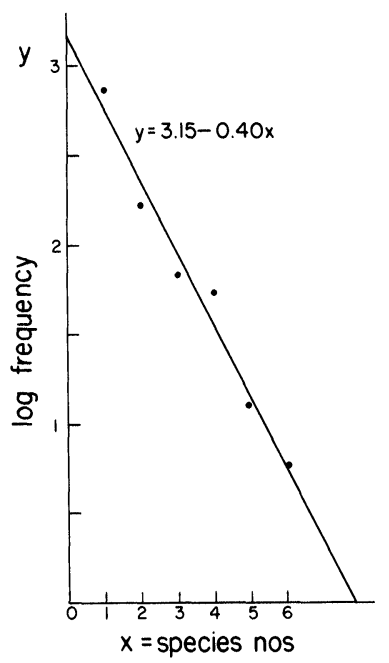

Fig. 1. Log frequency distribution and regression for the six paussid species trapped.

The log frequency was plotted, together with the calculated regression (Fig. 1). That the six species have a logarithmic distribution pattern can be seen by inspection.

The total catch (all species) for each sampling period is shown, together with the catches of the three most frequent species (Fig. 2). It would appear spinicoxis, sphaerocerus and cilipes frequencies are varying in parallel. The figures for these three species and the next most abundant, setosus, were tested for the significance of this apparent correlation by Kendall's coefficient of concordance (Siegel, 1956). The results:

$\mathrm{n}$ (number of sampling classes) $=20$

$\mathrm{K}$ (number of species) $=4$

$\mathrm{W}=0.66$

$\chi^{2}=50.22$

$\mathrm{df}=19$

$p<0.001$

There is a highly significant correlation in the periodic trends in the four species, these accounting for 98.2 percent of the material caught (W was calculated uncorrected for ties; with a correction 
Table 1. Days of sampling and numbers sampled to give an additional species.

\begin{tabular}{cccc}
\hline $\begin{array}{c}\text { Sampling } \\
\text { day }\end{array}$ & $\begin{array}{c}\text { Cumulative } \\
\text { total sampled }\end{array}$ & $\begin{array}{c}\text { Species } \\
\text { added }\end{array}$ & $\begin{array}{c}\text { Total } \\
\text { species }\end{array}$ \\
\hline 1 & 0 & 0 & 0 \\
4 & 1 & 1 & 1 \\
7 & 4 & 2 & 3 \\
44 & 52 & 1 & 4 \\
47 & 56 & 1 & 5 \\
116 & 220 & 1 & 6 \\
400 & 1063 & 0 & 6 \\
\hline
\end{tabular}

the value of $\chi^{2}$ would have been even larger). We can therefore analyse the total paussids with some confidence as reflecting the trends in each.

It is usual in tropical phenology to attempt to tie phenomena to the rainfall pattern (Karr, 1976). The major peak (Fig. 3) occurred in April-May, when the rains were building up to their maximum, but the minor peak of January-February occurred in the dry period when the rains, although increasing, did not reach the effective level, $10 \mathrm{cms} /$ month. The August trough coincided with the socalled "little dry season" but no simple correlation of paussid frequency with rainfall amounts was detected.

Table 1 gives the arrival day and cumulative total for the capture of the $\mathrm{i}^{\text {th }}$ species.

\section{Discussion}

It is likely the six species trapped represented all of the group present in the locality; extrapolation from the figures of Table 1 suggests an additional species should have been found, if present, before the 1000th individual was trapped.

The lognormal species distribution parallels that found in samples from Ghana of birds, ants, snakes and several other taxa (Leston, 1972): no explanation is offered here (but see Williams, 1964).

Paussids are emerging throughout the year but with marked fluctuations in frequency. The four most frequent species show parallel trends in their respective frequencies, indicative of the same set of factors influencing all. The peak corresponds closely 


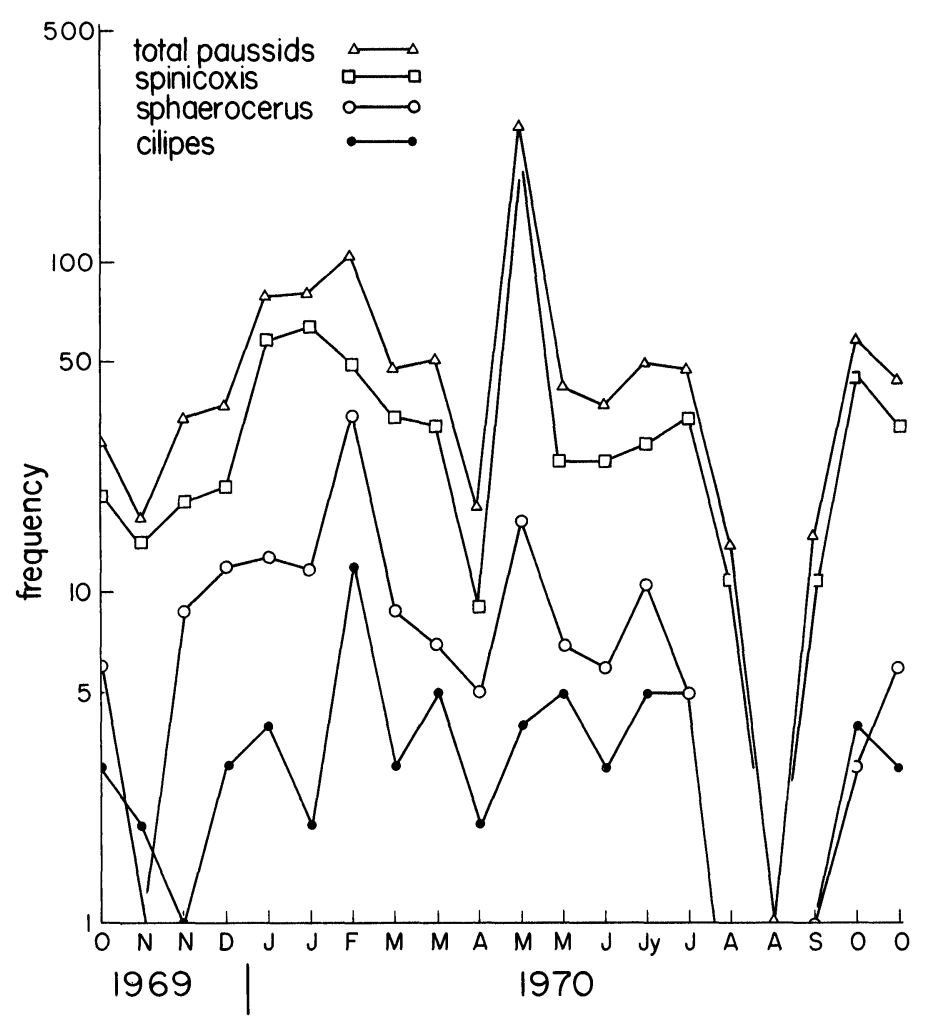

Fig. 2. Frequencies of all species together and the three most abundant species, in 20-day classes. Logarithmic.

to that found at Legon in the flight of male doryline ants (Leston, 1978), falling within the first wet sunny season (Gibbs \& Leston, 1970). It coincides too with that of alate sewing-ants, Oecophylla longinoda (Latreille), in the forest zone: again a wet sunny season event (Leston \& Gibbs, 1971).

But the apparent trimodality of the paussids does not fit just into the two wet sunny seasons of the forest zone although the October peak falls within the second of these. Were it not that a similar trimodality has been detected elsewhere it might have been dismissed as a peculiarity of the particular period sampled but a range of mantids sampled at Tafo, 35 miles north of Legon and in the forest zone, had a similar pattern (Leston, 1972). 


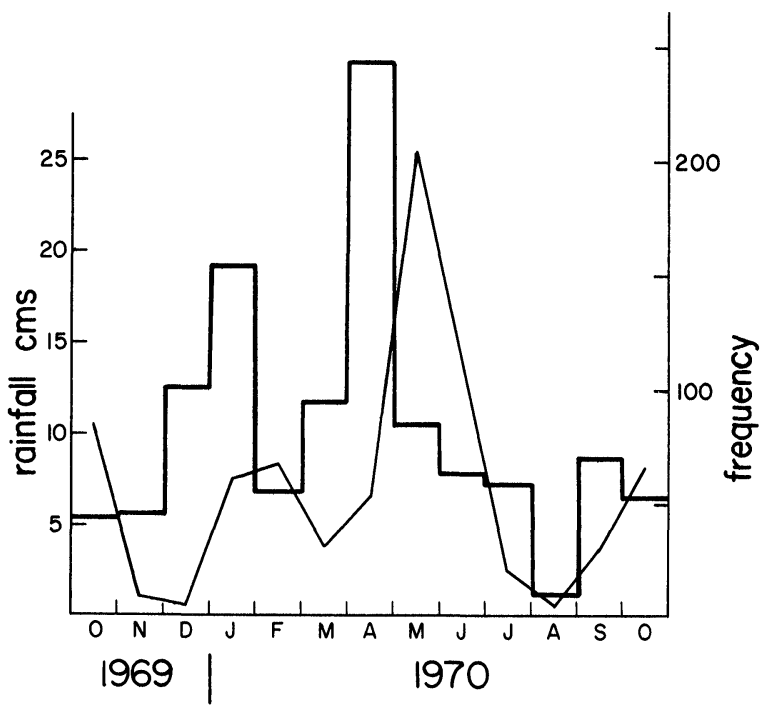

Fig. 3. Total paussids trapped (histogram) and rainfall, in monthly classes.

Paussids are entirely dependent for food upon ants (LeMasne, 1961). Ants in the West African forest zone are essentially predatory. Prey abundance there is more or less trimodal. There is a major peak in the first wet sunny season, around April, tied to the new flush and essentially comprising foliage feeders (augmented by decomposers). A second, less obvious, peak occurs in OctoberNovember, the second wet sunny season, and is again made up of foliage feeders, augmented this time by the fungivores. A third peak occurs around January, its date less reliable because of the variability in the intensity of the dry period from year to year: it sees a peak in insects associated with fruit or seeds (Gibbs \& Leston, 1970; Leston, 1972).

It is suggested that the ultimate factors concerned in the production of paussids are directly tied to the seasonal availability of prey to their host ants, just as in Mantodea the ultimate factors are available prey. Elsewhere (Leston, 1978) it is indicated the seasonal production of alate male doryline ants, as with paussids reaching a peak in the first wet sunny season, is geared to the optimal availability of prey to the workers of the species involved. Once again it has been found that the seasonal pattern in a tropical 
insect taxon cannot be explained by a simple wet season/dry season cycle: the biological periodicities - the true seasons - are those which follow from periodicities in rainfall and sunshine taken together (Gibbs \& Leston, 1970).

It is likely that the majority of the paussid species trapped at Legon came from the forest zone but nothing is known as to their host ants in West Africa. In view of their absence from the wide range of colonies of dominant, arboreal, ants sampled in Ghana (Leston, 1973b) it is probable their hosts are for the most part ground-nesting species.

\section{ACKNOWLEDGEMENTS}

My research has been supported by the Ghana Cocoa Growers' Research Association, the Cocoa, Chocolate and Confectionery Alliance (U.K.), the University of Ghana and the Research Foundation of the University of Connecticut.

\section{CONCLUSIONS}

1. Six paussid species were taken in an ultraviolet light-trap run for 400 days at Legon, Ghana, the catch totalling 1063.

2 . The frequencies of the trapped species had a lognormal distribution.

3. The frequencies showed parallel periodic changes between the species.

4. Peak emissions occur in the 1 st wet sunny period, lesser maxima in the 2nd wet sunny and the dry sunny periods of the GibbsLeston model.

5. The ultimate factor, it is suggested, is prey availability to the host ants.

\section{REFERENCES}

Darlington, P. J. (1950) Paussid beetles. Transactions of the American Entomological Society 76: 47-142.

GiBBS, D. G. \& LeSTON, D. (1970) Insect phenology in a forest cocoa-farm locality in West Africa. Journal of applied Eclogy 7: 519-548.

KARR, J. R. (1976) Seasonality, resource availability, and community diversity in tropical bird communities. The American Naturalist 110: 973-994.

LEMASNE, G. (1961) Recherches, sur la biologie des animaux myrmécophiles: observations sur le régime alimentaire de Paussus favieri Fairm., hôte de la fourmi Pheidole pallidula Nyl. C. R. Acad. Sci. Paris 253: 1356-1357. 
Leston, D. (1972) Insect interrelations in cocoa: a contribution to tropical ecology. Ph.D. thesis, University of Ghana.

Leston, D. (1973a) The flight behaviour of cocoa capsids (Hem., Miridae). Entomologia experimentalis et applicata 16: 91-100.

Leston, D. (1973b) The ant mosaic, tropical tree crops and the limiting of pests and diseases. PANS, London 19: 311-341.

LESTON, D. (1978) Dispersal by male doryline ants in West Africa. Ecology (in press).

Leston, D. \& GibBs, D. G. (1971) Phenology of cocoa and some associated insects in Ghana. Proceedings of the 3rd international Cocoa Research Conference, Accra, 1969: 197-204.

SIEGEL, S. (1956) Nonparametric statistics for the behavioral sciences. McGrawHill; New York.

Williams, C. B. (1964) Patterns in the balance of nature. Academic Press; London. 

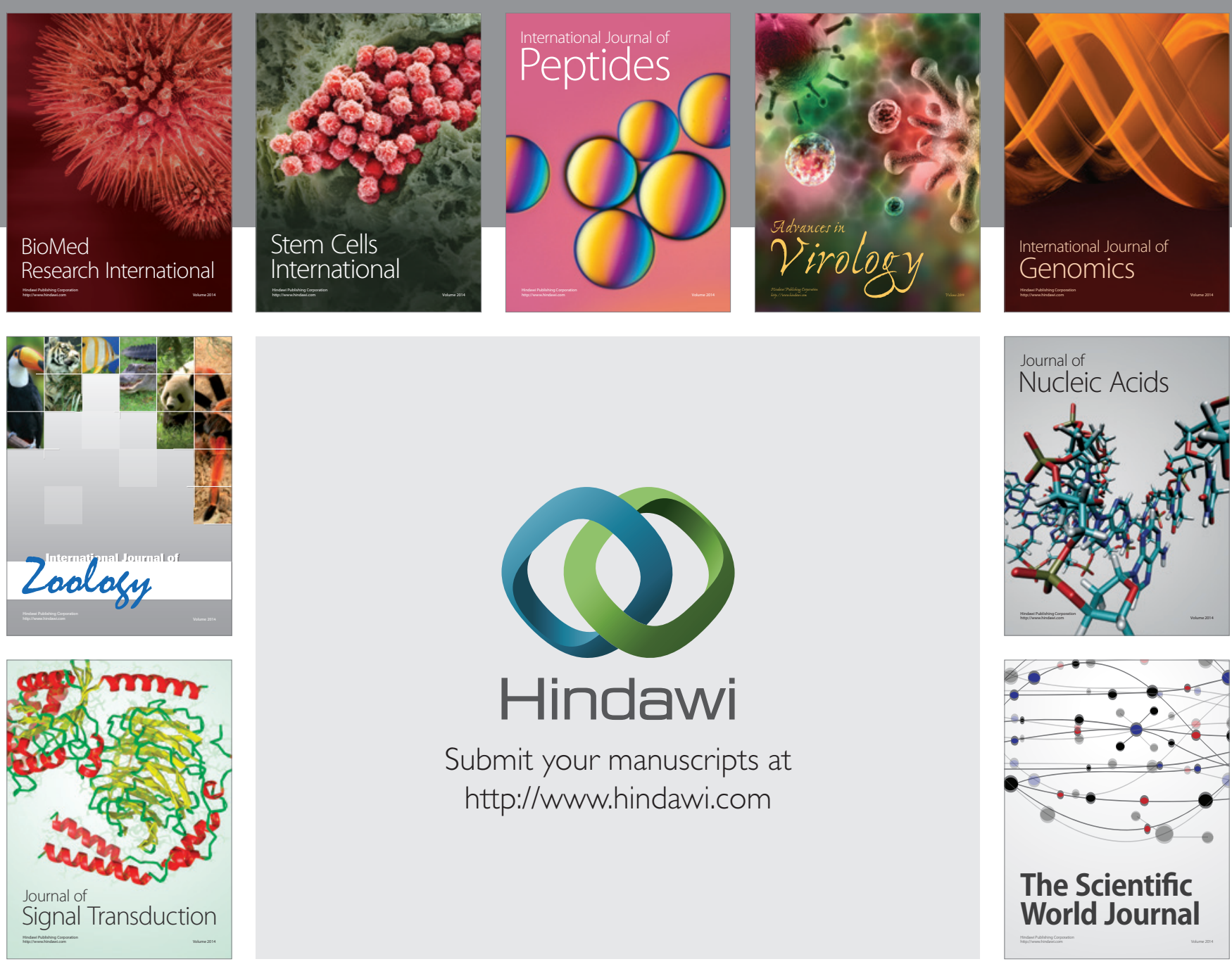

Submit your manuscripts at

http://www.hindawi.com
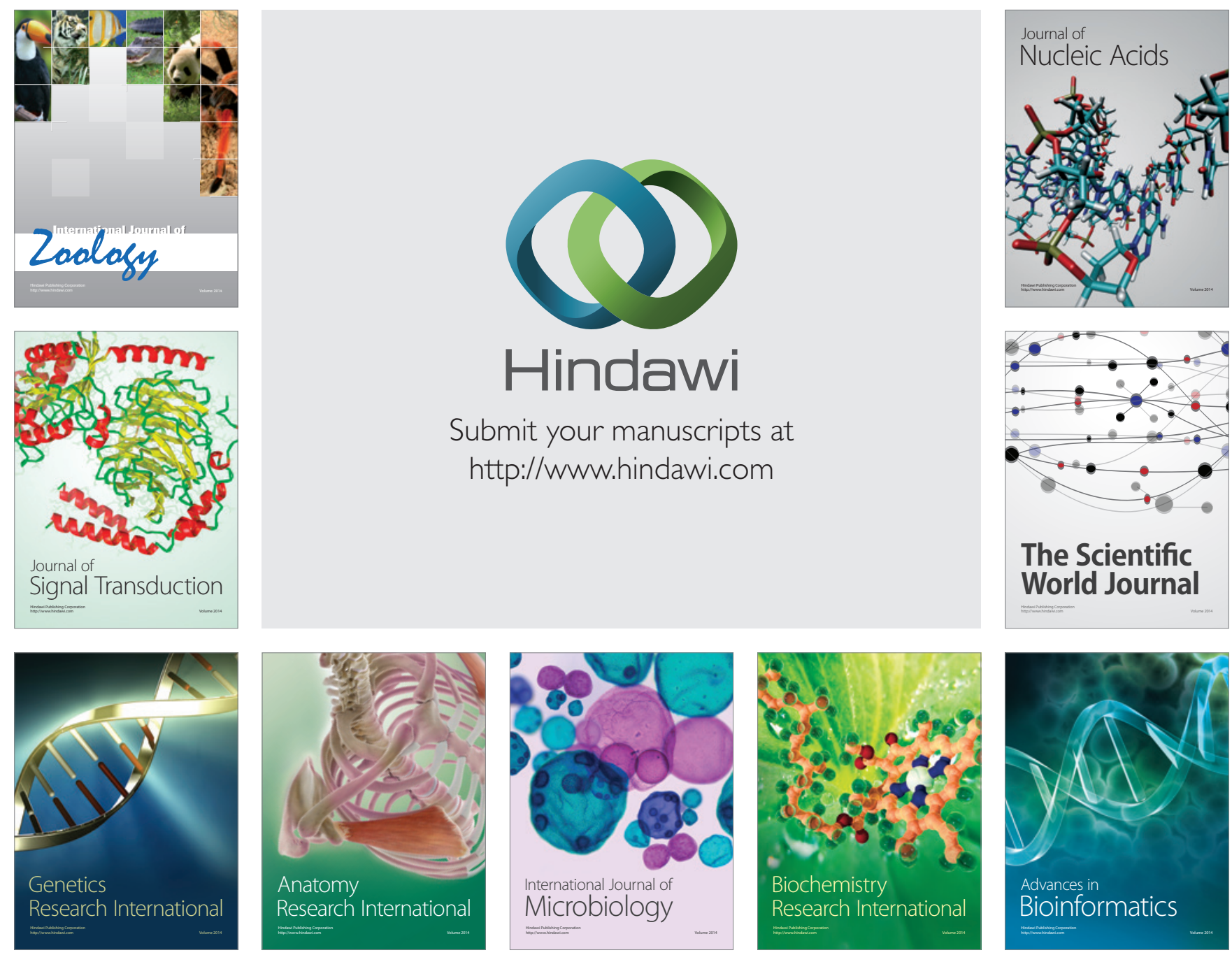

The Scientific World Journal
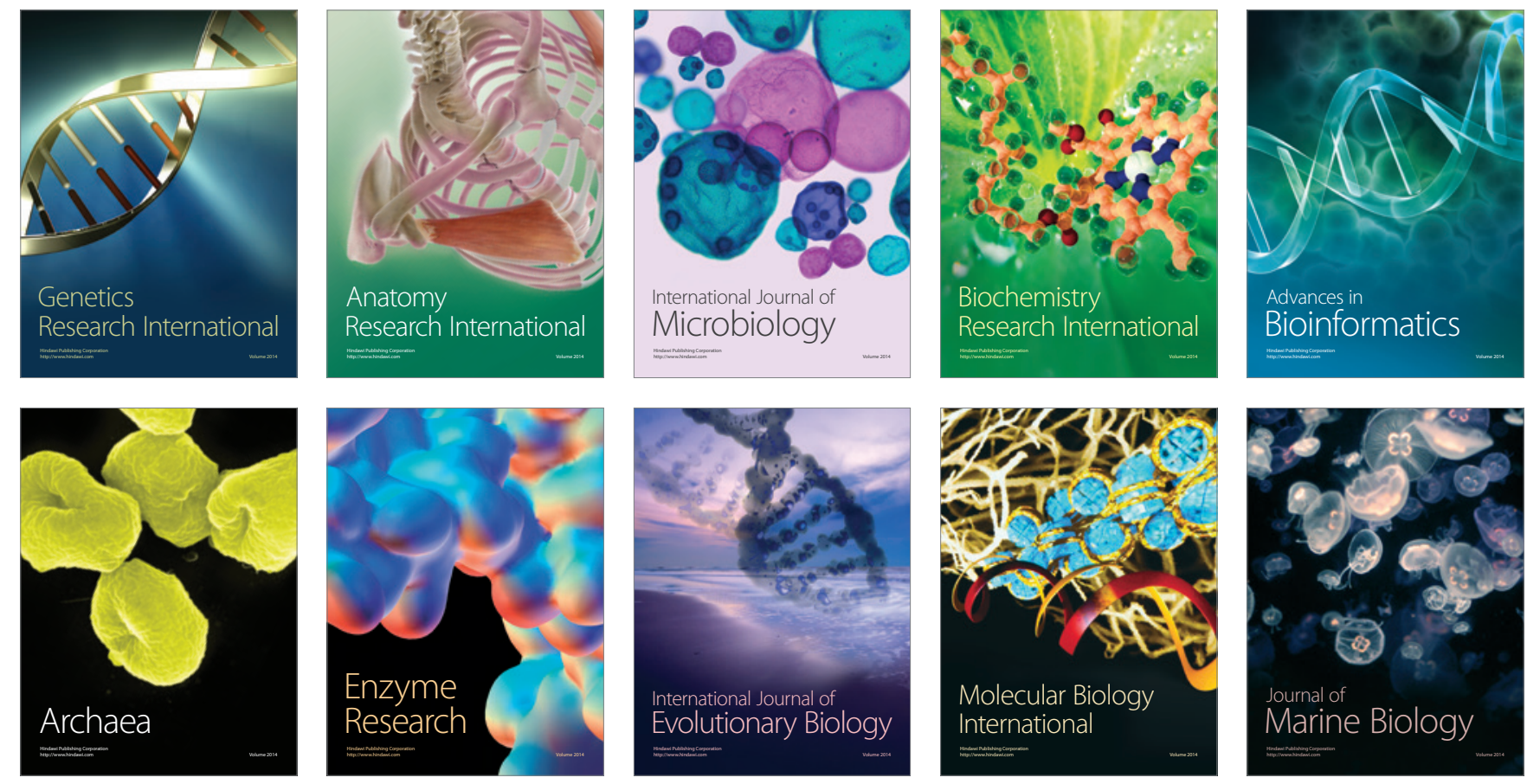